\title{
Adsorption Capacity of Low Cost Activated Carbon For Removal of Copper Ions From Aqueous Media
}

\author{
Shah Muhammad Haroon*, SammiaShahid, Fakhra Ashraf \\ Department of Chemistry, \\ University of Management and Technology, Lahore, Pakistan. \\ *muhammad.haroon@umt.edu.pk
}

\begin{abstract}
The ability of low cost activated carbon based on tamarind stone for the removal of copper ion from water was explored. Tamarind stone was converted into activated carbon by lean air carbonization and chemically activated by barium chloride. The factors affecting on adsorption process i-e particle size, concentration, and $p H$ were investigated. Maximum adsorption i-e 64\% of copper ions occurs at $100 \mathrm{mg} / \mathrm{L}$ initial concentration by $0.1 \mathrm{~g}$ of activated carbon having $149 \mu$ particle size. The adsorption of coppr(II) ions was higher at higher $\mathrm{pH}$ value i-e $21 \mathrm{mg} / \mathrm{L}$. Adsorption was found to be increased with increase in temperature due to endothermic nature .The potential of the prepared activated carbon for removal of copper ions from aqueous media was satisfactory.
\end{abstract}

Key Words: low cost adsorbent, activated carbon, copper ion, water purification, agricultural waste

\section{Introduction}

Water is essential for life existence on the earth. Without water survival on the earth is impossible. This is so because of its unique chemical and physical properties, low cost, abundantly available, non-toxic, environmental friendly nature.

There are many sources of water pollution. Most of them are city sewage and industrial waste which are discharged in rivers, sea and canals etc. Water quality is described on the basis of its chemical, biological, physical and parameters [1].

Groundwater $(\mathrm{GW})$ pollution by hazardous waste materials and chemicals which are improperly or used for agricultural purposes, has reached alarming levels over the past decade [2].

Toxic metals such as cadmium, mercury, arsenic and copper tend to accumulate in bottom sediments which are then remobilized through various processes and reach to biological chain, resulting acute and chronic ailments in human being [3].

Copper, an essential element in trace amount for human metabolism, but become toxic at above $2 \mathrm{mg} / \mathrm{L}$ [4]. Such higher concentrations causes irritation in mucous membranes, hair damage and may be source of necrotic variations in the kidneys and liver [5]. The major sources of copper in wastewaters is energy and electronic industries [4]. To remove such pollutants from groundwater, adsorption on different costly adsorbents like imported activated carbons, photochemical decomposition by UV radiations, zeolites, or aeration is usually applied, but such methods are costly $[6,7]$.The use of agricultural waste and products for the elimination of metals from queous 
media has been explored by many researchers [5, 8-11]. Activated carbon is an effective and competitive adsorbent for the elimination of toxic metals in tracesin aqueous media $[11,12]$.

\section{Material and Methods}

In present work all the chemicals used of analytical grade and made as Sigma Aldrich and Merck. The experimental work was done in three major steps which are given below.

\subsection{Preparation of low cost activated carbon Low cost activated carbon was prepared by the following five steps}

(a) Collection and Cleaning of raw material

Tamarind stone was collected from local market "Pappar Mandi" Lahore and then cleaned by with distilled water after sorting.

\section{(b) Carbonization}

Dried tamarind stone were subjected to carbonization in a Muffle Furnace at $500^{\circ} \mathrm{C}$ for 1 hour duration.

\section{(c) Grinding of carbonized material}

The carbonized material was converted into two sizes i-e. selected sieve sizes for both the date stone \& tamarind stone was 595 micron and 149 micron by pestle and mortar and with help of sieve shaker.

\section{(d) Activation}

A known amount weight of carbonized material was soaked in $\mathrm{BaCl}_{2}$ solution keeping impregnation ratio to $1: 4$ for 24 hours.

\section{(e) Washing and drying}

The resultant a was washed several times with distilled water, dried at $100^{\circ} \mathrm{C}$ for 4 hours and kept in an air tight container.

\section{(a) pH measurements}

\section{Characterization of activated carbon}

Few $200 \mathrm{mg}$ of adsorbent was soaked in $25 \mathrm{ml}$ double distilled water for 12 hours and resultant slurry was used to determine $\mathrm{pH}$ with the help of Hanna digital pH meter HI83141.

\section{(b) Fourier Transform Infra Red Spectroscopy}

The Fourier Transform Infra Red Spectroscopy (FTIR) spectra of the prepared activated carbon as well as standard activated carbons were recorded on a Varian 640-IR spectrophotometer ranging $400-4000 \mathrm{~cm}^{-1}$ by $\mathrm{KBr}$ disc method with fine pure $\mathrm{KBr}$ powder as reference.

\section{(c) Scanning Electron Microscopy}

The scanning electron microscopy (SEM) of low cost activated carbon was performed for surface morphology. 


\section{(a) Effect of concentration}

\section{Removal of copper ion by adsorbent}

Static batch experiment was used for the absorbance of $\mathrm{Cu}$ (II) ion from sample solution. $100 \mathrm{ml}$ of each solution ranging 10-100 mg/L was taken in $250 \mathrm{ml}$ reagent bottle and shaked with the 0.1 $\mathrm{g}$ of $149 \mu$ prepared activated carbon(adsorbent) in Stuart SI 400 incubator orbital shaker at $28.5^{\circ} \mathrm{C}$ having speed $100 \mathrm{rpm}$ for 1 hour. After one hour shaking the contents of reagent bottles was filtered and the concentration of copper ions in filtrate was determined spectrophotometrically using ammonia solution as complexing agent at absorption maxima $610 \mathrm{~nm}$.

\section{(b) Effect of particle size}

In order to study effect of particle size on adsorption $100 \mathrm{ml}$ of each solution ranging 10-100 $\mathrm{mg} / \mathrm{L}$ was taken in $250 \mathrm{ml}$ reagent bottle and shaked with the prepared activated carbon(adsorbent) of two different particle size $(149 \mu$ and $595 \mu)$ at $100 \mathrm{rpm}$ shaking speed in Stuart SI 400 incubator orbital at $28.5^{\circ} \mathrm{C}$ for 1 hour.

After one hour shaking the contents of reagent bottles was filtered and the concentration of copper ions in filtrate was determined spectrophotometrically using ammonia solution as complexing agent at absorption maxima $610 \mathrm{~nm}$.

\section{(c) Effect of temperature}

In order to study effect of temperature ranging from $20^{\circ} \mathrm{C}$ to $30^{\circ} \mathrm{C}$ on adsorption $100 \mathrm{ml}$ of each solution ranging $10-100 \mathrm{mg} / \mathrm{L}$ was taken in $250 \mathrm{ml}$ reagent bottle and shaked with the $0.1 \mathrm{~g}$ prepared activated carbon(adsorbent) of 149 micron particle size in Stuart SI 400 incubator orbital shaker for 1 hour.

After one hour shaking the contents of reagent bottles was filtered and the concentration of copper ions in filtrate was determined spectrophotometrically using ammonia solution as complexing agent at absorption maxima $610 \mathrm{~nm}$.

\section{(d) Effect of $\mathrm{pH}$}

Three different $\mathrm{PH}$ value $(4,7$, and 10) was selected for the study of adsorption at the constant temperature (28.4) and particle size (149). Three $250 \mathrm{ml}$ reagent bottle each containing $100 \mathrm{ml}$ of sample solution was taken in $250 \mathrm{ml}$ reagent bottle and their $\mathrm{pH}$ was adjusted to 4, 7, 10 separately using $0.1 \mathrm{M}$ acetic acid and $0.1 \mathrm{MNaOH}$ solution. Then the solutions having $40 \mathrm{mg} / \mathrm{L}$ of copper(II) ions were shaked with $0.1 \mathrm{~g}$ of the prepared activated carbon (adsorbent) in Stuart SI 400 incubator orbital shaker having shaking speed 50rpm for 1 hour..

After one hour shaking the contents of reagent bottles was filtered and the concentration of copper ions in filtrate was determined spectrophotometrically using ammonia solution as complexing agent at absorption maxima $610 \mathrm{~nm}$.

\section{Results and Discussion}

Since $\mathrm{pH}$ is an important factor which affects the adsorption significantly so it is necessary to determine $\mathrm{pH}$ of activated carbon. The $\mathrm{pH}$ of the prepared activated carbon was found acidic (6.41). 


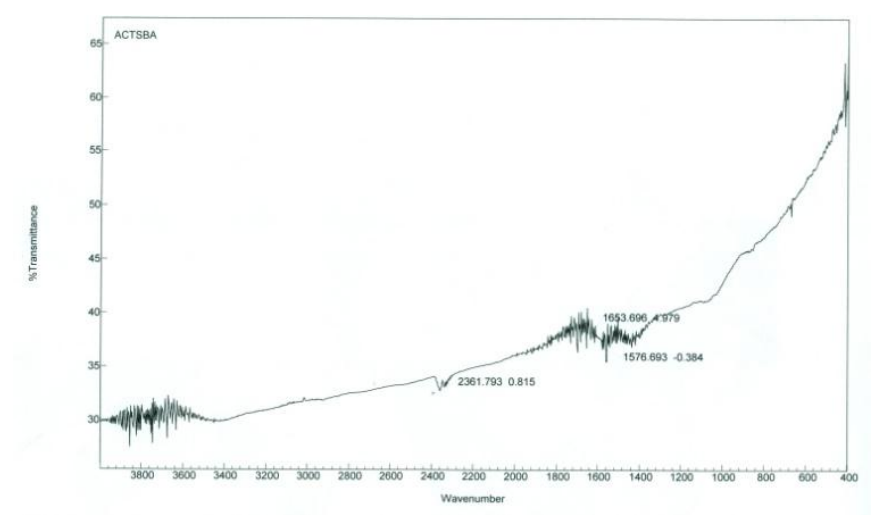

Figure 1. FTIR spectra of activated carbon based on tamarind stone

It was reported by Yasmin et al. [13]that almost all activated carbons are porous with little amounts of chemically attached hydrogen and oxygen which is shown in the spectra of the prepared activated carbon. Figure 1 shows attachment of water molecule in activated carbon due to its adsorption property.

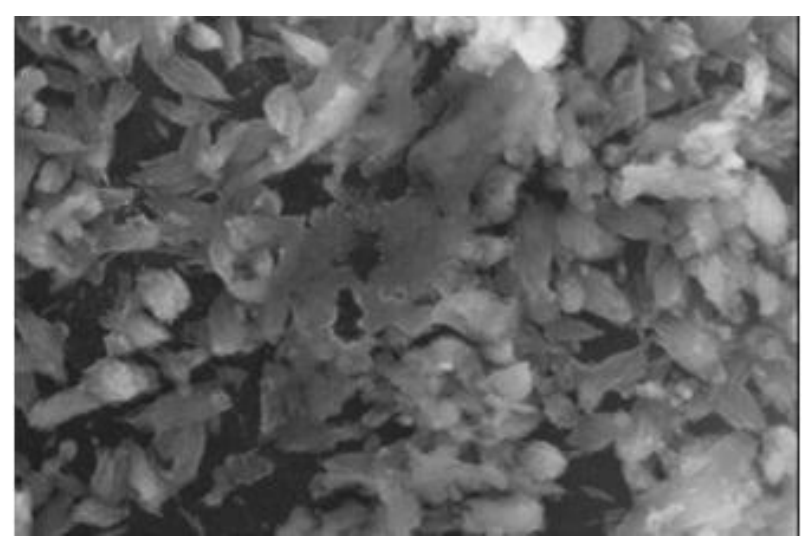

Figure 2. Scanning electron microscope image of activated carbon

Scanning electron microscopic image (figure 2) of activated carbon shows the porosity and high surface area of activated carbon by chemical activating agent $\mathrm{BaCl}_{2}$ Amudaetal. [14] also showed that coconut shell based activated carbon activated by $\mathrm{BaCl}_{2}$ has high surface area $632 \mathrm{~m}^{2} / \mathrm{g}$ than commercial coconut shell based activated carbon $628 \mathrm{~m}^{2} / \mathrm{g}$. 


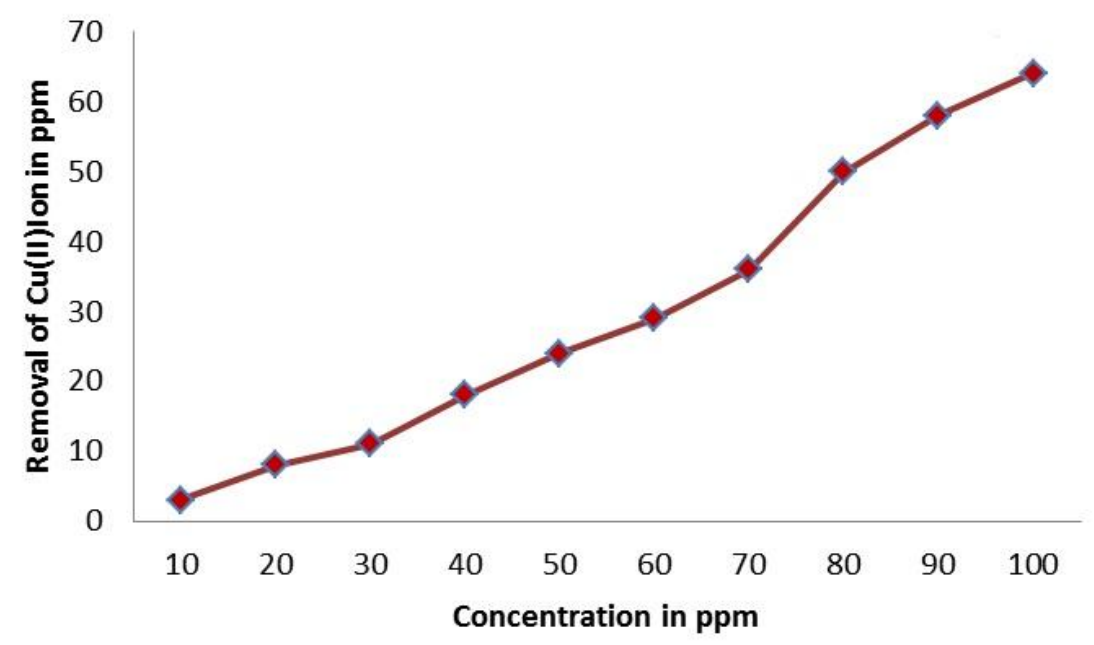

Figure 3. Effect of initial aqueous solution of $\mathrm{Cu}(\mathrm{II})$

Based on figure 3, it is cleared that adsorption increases with increase in concentration of copper(II) ion. It was reported by Danish et al. [15] found that lower initial concentration has less interaction with surface of activated carbon.

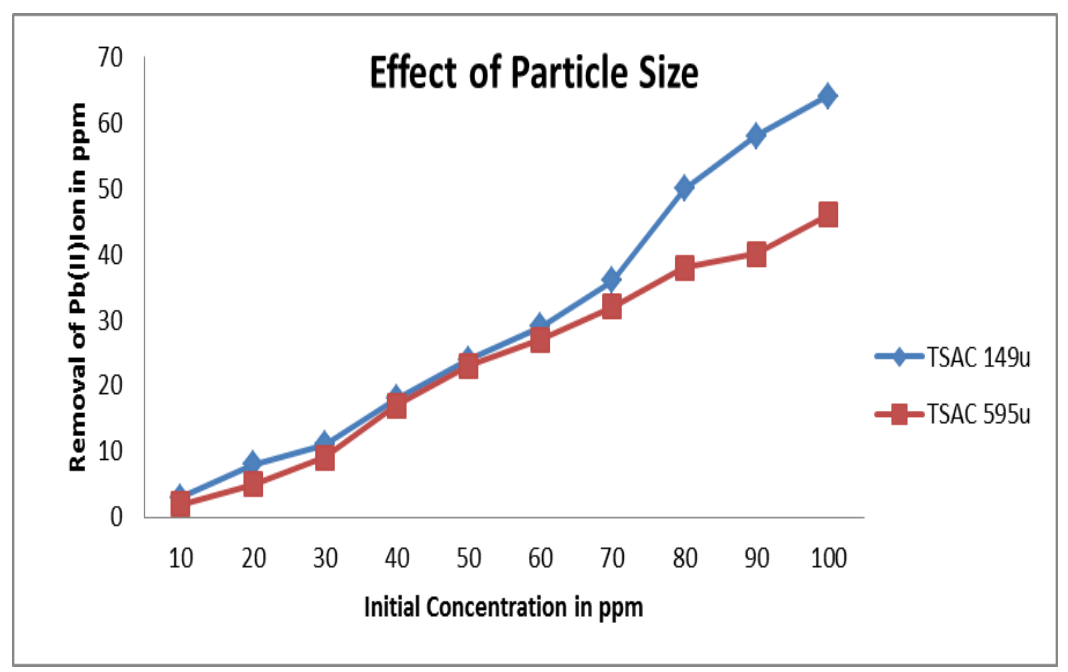

Figure 4. Effect of particle size on adsorption

Adsortion increases with increase in surface area. Figure 4 clearly shows small particle size activated carbon i-e 149 micron has higher adsorption capacity as compared to small surface area activated carbon i-e 595 micron. Maiti et al. [16] reported maximum removal of arsenate by large surface area activated carbon found optimum $0.75 \mathrm{~mm}$ as compared smaller surface areal $\mathrm{mm}$ activated carbon. 


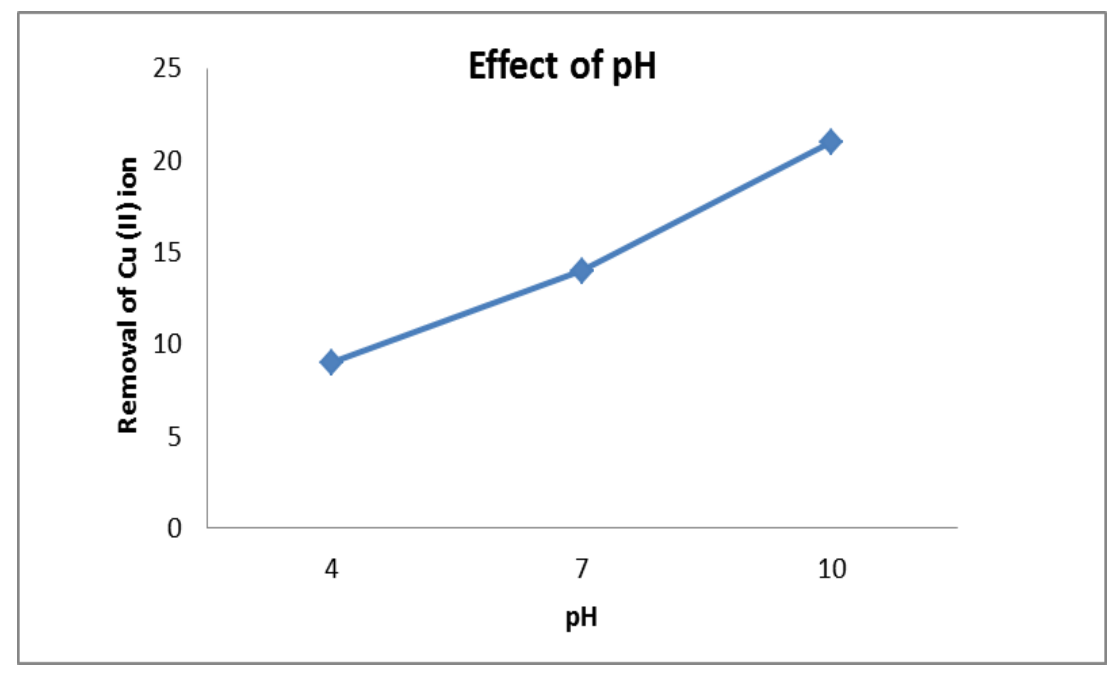

Figure 5. Effect of $\mathrm{pH}$ of aqueous solution of $\mathrm{Cu}(\mathrm{II})$ ions on their adsortion using activated carbon

The effect of $\mathrm{pH}$ is clearly showing that removal of copper ionis increasing with increase in $\mathrm{pH}$ of medium as it is shown in figure 5 shows as copper(II) ions are smaller in size ( $8.38 \AA$ ) therefore, they enter easily at basic $\mathrm{pH}$ into smaller pores and have competition at acidic $\mathrm{pH}$ with $\mathrm{H}^{+}$ions. $\mathrm{Ph}$ higher than 6.0, insoluble copper hydroxide begins precipitating So, both precipitation and adsorption are mechanisms to eliminate copper(II) in aqueous media [17].

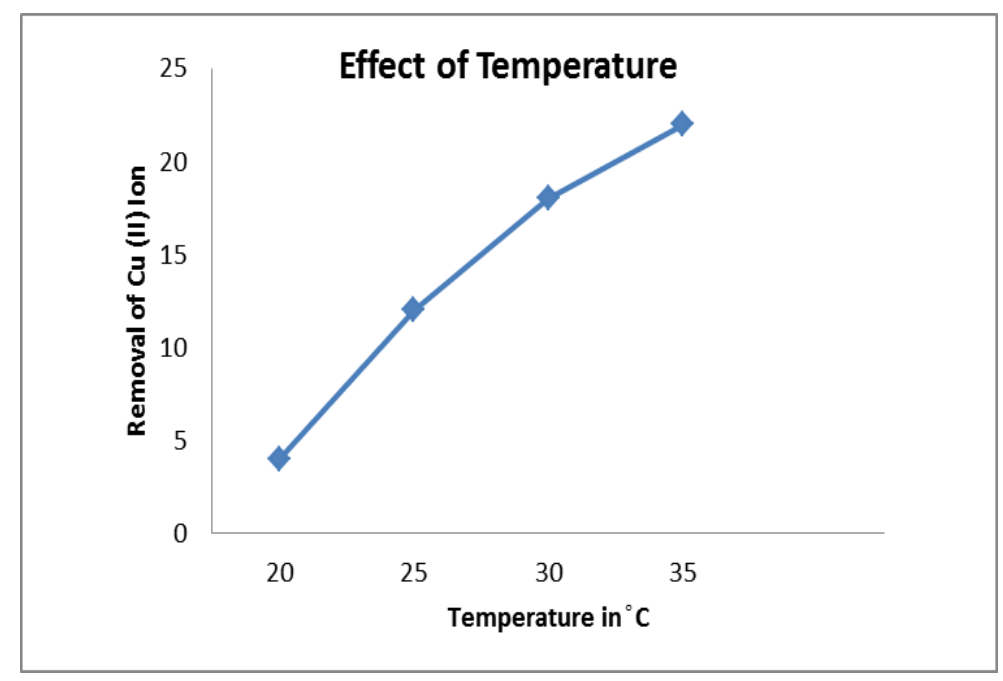

Figure 6. Effect of temperature on adsorption of copper(II) ions 
The adsorption of copper (II) ion at various temperatures are shown in Figure 6 with respect to initial metal ion concentration. It is clear that the percentage adsorption increased with increasing temperature [18].

\section{Conclusion}

Cheap tamarind stone being an agricultural waste which is locally and abundantly available is a potential resource for the manufacturing of activated carbon for nationwide use.

The adsorption is significantly affected by $\mathrm{pH}$, concentration, temperature and particle size of adsorbent. Maximum \%age of copper ion which was removed was 64 against $0.1 \mathrm{~g}$ of adsorbent dose. The performance of activated carbon is quite encouraging and can be used for removal of heavy metal ions from aqueous solutions.

\section{References}

[1] Singh KP, Malik A, Sinha S. Water quality assessment and apportionment of pollution sources of Gomti river (India) using multivariate statistical techniques - a case study. Anal Chim Acta. 2005;538(1):355-74.

[2] Bagtzoglou AC, Dougherty DE, Tompson AF. Application of particle methods to reliable identification of groundwater pollution sources. Water Resour Manage. 1992;6(1):15-23.

[3] Förstner U, Wittmann GT. Metal pollution in the aquatic environment, 486 S., 102 Abb., 94 Tab. Berlin-Heidelberg-New York: Springer-Verlag;1979.

[4] Horsfall Jr M, Abia A, Spiff A. Kinetic studies on the adsorption of $\mathrm{Cd} 2+, \mathrm{Cu} 2+$ and $\mathrm{Zn} 2+$ ions from aqueous solutions by cassava (Manihot sculenta Cranz) tuber bark waste. Bioresource Technology. 2006;97(2):283-91.

[5] Maguie KA, Nsami NJ, Daouda K, Randy CN, Mbadcam KJ, Maguie K, et al. Adsorption study of removal of Copper (II) Ions using activated carbon based canarium schweinfurthii shells impregnated with ZnCl2. IRA-Int J Appl Sci. 2017;8(1):18-30.

[6] Beltran FJ, García-Araya JF, Acedo B. Advanced oxidation of atrazine in water-II. Ozonation combined with ultraviolet radiation. Water Res. 1994;28(10):2165-74.

[7] Wood PR, DeMarco J. Effectiveness of various adsorbents in removing organic compounds from water; paet I, removing purgeable halogenated organics. In: M J Mcguire and I H Suffet Eds. Activated carbon adsorption of organics from the aqueous phase, volume 2. Ann Arbor, MI: Ann Arbor Science; 1981.

[8] Bouchelta C, Medjram MS, Bertrand O, Bellat J-P. Preparation and characterization of activated carbon from date stones by physical activation with steam. J Anal Appl Pyrolysis. 2008;82(1):70-7.

[9] Chowdhury ZZ, Zain SM, Khan RA, Arami-Niya A, Khalid K. Process variables optimization for preparation and characterization of novel adsorbent from lignocellulosic waste. BioResources. 2012;7(3):3732-54.

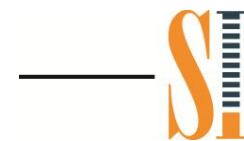

SCIENTIFIC INQUIRY AND REVIEW 47 
[10] Ahmedna M. Granular activated carbons from agricultural by-products: Preparation, properties, and application in cane sugar refining. 2000. LSU Agricultural Experiment Station Reports. 456. Available from: http://digitalcommons.lsu.edu/agexp/456

[11] Hassan A, Youssef A. Preparation and characterization of microporous $\mathrm{NaOH}$-activated carbons from hydrofluoric acid leached rice husk and its application for lead (II) adsorption. Carbon Lett. 2014;15(1):57-66.

[12] Momčilović M, Purenović M, Bojić A, Zarubica A, Ranđelović M. Removal of lead (II) ions from aqueous solutions by adsorption onto pine cone activated carbon. Desalination. 2011;276(13):53-9.

[13] Yasmin T, Rashid MA, Saeed T. Activated carbon from the pericarp of peanut. Pak J Agri Sci. 1999;36(1-2):30-32.

[14] Amuda O, Ibrahim A. Industrial wastewater treatment using natural material as adsorbent. Afr J Biotechnol. 2006;5(16):1483-1487.

[15] Danish M, Sulaiman O, Rafatullah M, Hashim R, Ahmad A. Kinetics for the removal of paraquat dichloride from aqueous solution by activated date (Phoenix dactylifera) stone carbon. J Dispersion Sci Technol. 2010;31(2):248-59.

[16] Maiti A, Agarwal V, De S, Basu JK. Removal of As (V) using iron oxide impregnated carbon prepared from Tamarind hull. J Environ Sci Health, Part A. 2010;45(10):1207-16.

[17] Mathialagan T, Viraraghavan T. Adsorption of cadmium from aqueous solutions by perlite. J Hazard Mater. 2002;94(3):291-303.

[18] Özer A, Özer D, Özer A. The adsorption of copper (II) ions on to dehydrated wheat bran (DWB): determination of the equilibrium and thermodynamic parameters. Process Biochem. 2004;39(12):2183-91. 